\title{
Salt-wedge intrusion of seawater and its implication for phytoplankton dynamics in the Yura Estuary, Japan
}

\section{$\operatorname{AUTHOR}(S)$ :}

Kasai, Akihide; Kurikawa, Yoshiro; Ueno, Masahiro; Robert, Dominique; Yamashita, Yoh

\section{CITATION:}

Kasai, Akihide ... [et al]. Salt-wedge intrusion of seawater and its implication for phytoplankton dynamics in the Yura Estuary, Japan. Estuarine, Coastal and Shelf Science 2010, 86(3): 408-414

\section{ISSUE DATE:}

2010-02-10

URL:

http://hdl.handle.net/2433/97921

\section{RIGHT:}

c 2009 Elsevier Ltd. All rights reserved.; This is not the published version. Please cite only the published version.; この論文は出版社版でありませ ん。引用の際には出版社版をご確認ご利用ください。 
Salt-wedge intrusion of seawater and its implication for phytoplankton dynamics in the Yura Estuary, Japan

Akihide Kasai $^{\mathrm{a}^{*}}$, Yoshiro Kurikawa ${ }^{\mathrm{a}}$, Masahiro Ueno ${ }^{\mathrm{b}}$, Dominique Robert ${ }^{\mathrm{b}}$ and Yoh Yamashita ${ }^{\mathrm{b}}$

${ }^{a}$ Kyoto University, Graduate School of Agriculture, Oiwake, Kitashirakawa, Sakyo, Kyoto, 606-8502, Japan

${ }^{\mathrm{b}}$ Kyoto University, Field Science Education and Research Center, Nagahama, Maizuru, 625-0086, Japan

* Corresponding author: Akihide Kasai

Tel: +81-75-753-6314

Fax: +81-75-753-6468

E-mail: kasai@kais.kyoto-u.ac.jp 


\begin{abstract}
We monitored hydrographic and biological conditions in the Yura Estuary and its coastal area from April 2006 to March 2008. Hydrographic conditions changed seasonally, and were mainly determined by river discharge and sea level, with tides playing a minor role. In summer, when river discharge was low and sea level was high, a salt-wedge regime was established until $\sim 18 \mathrm{~km}$ upstream from the river mouth. Seawater intrusion into the river was however restricted in winter, when the river discharge was high and sea level was low. Water stratification caused by the seawater intrusion played an important role in phytoplankton dynamics. Phytoplankton developed in the middle layer of the estuary utilizing riverine nutrients, corresponding to the seawater intrusion into the bottom layer in summer. In winter, however, the phytoplankton production remained low in both estuary and sea.
\end{abstract}

Keywords: estuarine dynamics, phytoplankton, river discharge, seasonal changes, stratification 


\section{Introduction}

Many comparative studies have shown that production in estuaries is highest in marine systems (e.g. Boynton et al., 1982). Estuaries support numerous commercially exploited populations of nektonic and benthic organisms, as well as sea birds. They are therefore recognized as playing an important ecosystemic role, notably at the land-sea interface, together with generating high fisheries production. These systems are often influenced by human activity, since most of the world's population concentrates around estuaries and coastal areas (Mann, 2000). Increased loading of anthropogenic nutrients and organic matter stimulates primary production and induces environmental problems such as eutrophication, hypoxia, harmful or nuisance algal blooms, and changes in food web structure, especially in poorly flushed estuaries (e.g. Wolanski, 2007). For example, in the Dneister and Dneiper estuaries, fish stocks have collapsed as a result of dam construction in the river basins (Drinkwater and Frank, 1994). Adequate management of estuarine resources is therefore required for maintaining healthy ecosystem and their sustainable use.

Physical dynamics play a critical role in the regulation of estuarine biological production, material transport and consequently, water quality. Substantial advancement in our understanding of estuarine dynamics could be achieved with sustained research. Two-dimensional circulation in the axial (longitudinal and vertical) plane has been the primarily focus of conventional studies, since longitudinal transport of salt and other materials was considered the most important feature among estuarine processes. However, recent studies have shown that the physical structure is three-dimensional in wide estuaries where horizontal scales are larger than the internal Rossby radius of deformation (Kasai et al., 2000). Estuaries are classified into three types based on their longitudinal salinity distribution and consequent flow characteristics: highly stratified or salt wedge, partially mixed, and vertically homogeneous or well-mixed (e.g. Dyer, 1996). The type of a given estuary is generally determined by its tidal regime, river discharge, and by the interaction of these two factors with the topography. A proper understanding of these characteristics provides the baseline for studies on phytoplankton dynamics in estuarine systems.

The magnitude and seasonality of phytoplankton production were well studied in partially mixed and vertically homogeneous estuaries, which are ubiquitous in Europe and North America. However, in highly stratified estuaries, there are few reports about processes driving primary production (Thompson, 1998; Harrison et al., 2008). Coastal zones of the Sea of Japan (Fig. 1) are generally characterized by a tideless regime (Nishida, 1980). The Sea of Japan is the semi-enclosed sea north of Japanese 
Islands. Relative to its total surface, the mouth of the Sea of Japan (Tsushima Strait) is so narrow that the tides rapidly decay when they pass through it (Unoki, 1993). In these low tide conditions, the buoyancy input from rivers prevails on tidal mixing, and estuaries thus tend to be stratified.

This study was conducted in the Yura Estuary, a tideless estuary facing to the Sea of Japan (Fig. 1). Compared with previous studies realized in the Swan and Pearl estuaries (Thompson, 1998; Harrison et al., 2008), which are tideless estuaries characterized by large urban development in their lower reaches, anthropogenic impact is relatively small in the Yura Estuary. The scales of catchment area, length and urbanization of the Yura Estuary are representative of most estuaries on the Sea of Japan side. The precise mechanisms driving primary production, as well as spatio-temporal variability in phytoplankton abundance in these estuaries remain largely unknown. The objective of this study was therefore to assess seasonal variability in hydrographic and biological conditions in the estuary from monthly surveys conducted over a period of two years. We particularly focused on the magnitude of seawater intrusion and its effect on phytoplankton dynamics.

\section{Materials and methods}

The Yura is a $146 \mathrm{~km}$ long river, located in central Japan, comprising a catchment area of approximately $1880 \mathrm{~km}^{2}$ (Fig. 1). The annual average discharge of the Yura River is $\sim 50 \mathrm{~m}^{3} \mathrm{~s}^{-1}$. On the Sea of Japan side, northwesterly winter winds off the Asian continent bring heavy snow, making the catchment area one of the snowiest regions in Asia. In contrast, the area is subjected to cyclonic rain depressions in summer. The river discharge is therefore high in winter and early spring because of snow melting, while generally low in summer and autumn with sudden increases. It is therefore expected that the balance between stratification and mixing changes seasonally.

The Yura Estuary flows into the Sea of Japan (Fig. 1). Its lowermost $10 \mathrm{~km}$ are strait and 100-500 $\mathrm{m}$ wide with a 3-5 $\mathrm{m}$ deep, nearly flat river bed concluding in a shallow sill at the mouth. Seawater easily intrudes into the river, since the riverbed is lower than the sea surface until $20 \mathrm{~km}$ upstream from the river mouth. The breakpoint bar forms the essential feature of a bar-built estuary, making the water mixed at the river mouth. The typical tidal range in the estuary is less than $0.5 \mathrm{~m}$, so that the Yura Estuary is classified as a microtidal estuary. Therefore the effects of tidal currents on the physical and biological conditions are negligible.

Monthly surveys were conducted from April 2006 to March 2008 in the lower part of the Yura River and coastal area of Tango Sea (Fig. 1c). The observations were 
carried out at every $2 \mathrm{~km}$ from the river mouth until $22 \mathrm{~km}$ upstreamside at the mid-channel, and at 5, 10, 15, 20, 25, 30, 40, 50 and $60 \mathrm{~m}$ depth along the extension of the river-line in the sea area. However, sampling was skipped at the uppermost three stations in summer, because a temporary weir is set at about $18 \mathrm{~km}$ upstreamside from the rivermouth to prevent saltwater intrusion.

Vertical profiles of temperature, salinity and chlorophyll fluorescence were obtained using a CTD profiler (Compact-CTD, Alec Electronics) at each station. Water samples were taken from the surface, middle and bottom layers at selected stations (open circles in Fig. 1c). All water samples were filtered through precombusted GF/F filters $\left(450^{\circ} \mathrm{C}, 4 \mathrm{~h}\right)$. Filters were extracted in the dark for $12 \mathrm{~h}$ in acetone $90 \%$, and Chlorophyll $a$ and pheophytin concentrations were measured using a calibrated fluorometer (Turner Designs, Trilogy). The chlorophyll fluorescence obtained by the CTD profiler was then calibrated using the measured Chlorophyll $a+$ pheophytin concentrations, as these variables were significantly correlated $\left(r^{2}=0.72\right)$. The water taken from July 2007 to March 2008 was used for nutrient (nitrate and nitrite) concentration analysis using an AutoAnalyzer (Bran-Luebbe, TRACSS 2000).

Daily mean river discharge (measured in Fukuchiyama, $37 \mathrm{~km}$ upstream from the river mouth - Fig. 1b) and sea level (measured in Maizuru, $8 \mathrm{~km}$ southeast from the river mouth - Fig. 1c) data were obtained from the Ministry of Land, Infrastructure, Transport and Tourism, and the Meteorological Agency, respectively.

\section{Results}

\subsection{Hydrographic conditions}

The hydrographic conditions considerably differed between winter and summer (Fig. 2). Freshwater occupied the lower part of the river and no seawater intrusion occurred during the high discharge periods (normal winter and early spring). The water was well mixed and homogeneous in both the river and sea, which were separated by a strong salinity front at the river mouth. The front was also detected from the temperature distribution, as low temperature was observed in the river $\left(\sim 5^{\circ} \mathrm{C}\right)$, while high temperature prevailed in the sea $\left(\sim 10{ }^{\circ} \mathrm{C}\right)$. In summer, however, hydrographic conditions changed drastically. Seawater intruded into the river through the bottom layer as a salt wedge. A sharp halocline then indicated the estuary was strongly stratified. In both the surface and bottom layers, salinity remained constant along the estuary except for zones at the tip of the wedge and the river mouth. In contrast to winter, freshwater temperature was equivalent or higher than that of the seawater.

Figure 3 a displays the time change in the salt wedge distance. In this study, the 
salt wedge distance is defined as the distance from the river mouth to the tip of the salt wedge, which salinity is 5 at the bottom. Seawater intrusion showed clear seasonal variations, being generally large in summer and small in winter. In highly stratified estuaries, the intrusion strength of the salt wedge is generally dependent on the river discharge, sea surface height and inclination of the riverbed. The former two factors change with time, but the latter is fixed. Figure $3 \mathrm{~b}$ and $3 \mathrm{c}$ show temporal variability of the river discharge in Fukuchiyama and sea level in Maizuru, respectively. The river discharge was generally high in winter and early spring due to melting snow. However, the unusual low snow precipitations led to low river discharge from the end of 2006 to the beginning of 2007. Several sudden peaks caused by large precipitations were recorded in summer, but average discharge was lower than that in winter. Sea surface height showed clearer seasonal trends with respective high and low levels in summer and winter, although short-term changes were also observed. An adequate correlation between these two parameters and the strength of the seawater intrusion were estimated from a multiple regression analysis $\left(r^{2}=0.79\right.$, Fig.4). The larger absolute value of standard partial regression coefficient of the river discharge $(0.76)$ indicates a stronger effect of the river discharge relative to sea level $(0.25)$. When the discharge was low, the salt wedge could penetrate further inland than when it was high. The seawater intrusion temporarily retreated after sudden increases in the river discharge, which were caused by heavy summer rain (July 2006 and July 2007). The smaller but significant correlation between the sea level and intrusion strength indicates that intrusion was stronger in summer when the sea level was high. The significant correlations synthetically signify that the strength of the seawater intrusion into the Yura River is primarily controlled by river discharge and sea level height.

\subsection{Nutrients and phytoplankton distribution}

Phytoplankton abundance showed clear spatial and seasonal variations, corresponding to the physical structure of the water column. In winter, chlorophyll concentration was low $\left(<10 \mu \mathrm{g} \mathrm{L}^{-1}\right)$ in both river and sea (Figs. 2 and 3). In summer, on the other hand, chlorophyll concentration was generally high in the river $\left(>10 \mu \mathrm{g} \mathrm{L}^{-1}\right)$, but low in the sea. Phytoplankton bloomed in the river in August and September. The longitudinal chlorophyll distribution during summer shows that a chlorophyll maximum was generated in the middle layer of the river, although the concentration was high at all depths at the river mouth (Fig. 2). This mid-layer chlorophyll maximum corresponded to the halocline. During most cruises in summer, the chlorophyll maximum was observed just below the halocline (Fig. 5). Chlorophyll concentration increased in late 
spring and summer, following the development of the halocline. In addition, the mid-layer chlorophyll maximum disappeared in July 2006 and July 2007, when the salt wedge retreated due to sudden increases in freshwater discharge (Fig.3).

Nutrient concentrations were constantly higher in the river than in the sea (Fig. 3e). There were no clear seasonal trends. However, during the stratified season, the nutrient distribution corresponded well to salinity distribution. Nitrate concentrations generally decreased with depth, changing from $>20 \mu \mathrm{M}$ in the surface brackish water to $<10 \mu \mathrm{M}$ in the bottom salty water (Fig. 6). The other notable feature is that the nutrient concentration decreased at the river mouth. Figure 7 shows spatial variations in nutrients and chlorophyll concentrations along the salinity. The nitrate concentrations observed in the river and sea closely followed a linear mixing line, with the exception of the values measured at the river mouth falling well below the line (Fig. 7a). This characteristic was paralleled by a surface chlorophyll concentration higher at the river mouth than at any other station (Fig. 7b). These trends of apparent nutrient decrease and chlorophyll increase at the river mouth were detected in the observations in August and September, when phytoplankton was abundant in the river (Figs. 3d and 6).

\section{Discussion}

The hydrographic conditions in the Yura River Estuary showed strong seasonal variability (Fig. 3). In summer, salt wedge intrusion was established with drastic salinity change at the interface (Fig. 5). The lack of strong tidal currents prevented mixing between lower saline waters and the upper freshwater layer. As the freshwater flow changed seasonally and temporally, the position of the tip of the salt wedge moved up and down the estuary (Fig. 3). These variations are mainly due to the northwesterly winter monsoon and summer heavy rain. Previous studies on the continental estuaries influenced by large river discharges have reported similar seasonal variations. In the Mississippi River estuary, the tip of the salt wedge migrates 100 to 200 miles annually (Mann, 2000). Ibanez et al. (1997) showed that salt wedge regimes are established at times of below-average freshwater input in the estuaries of the Rhone and Ebro Rivers, which flow into the Mediterranean Sea. On the contrary, the salt wedge is forced downstream or even washed away at times of high freshwater input. The hydrographic conditions of the Swan and Pearl estuaries are also affected by the river discharge and drastically change between dry and wet seasons (Thompson, 1998; Harrison et al., 2008). The Yura Estuary is classified into the same type, although the river discharge is lower than those of the abovementioned estuaries.

Short-term variability in the hydrodynamics and phytoplankton distribution 
caused by heavy summer rain is another important feature of the Yura Estuary (Fig. 3). Compared to continental countries, Japan is characterized by a relatively narrow stripe of mountainous land. This implies that most of its rivers bear a strong altitude gradient from the origin to the mouth, leading to short residence time of rainwater, as well as strong and rapid variations in river discharge. These sudden changes in turn impact estuarine physical and biological dynamics. For instance, Sugimoto et al. (2004; 2006) and Suzuki et al. (2009) respectively showed that the physical, chemical and biological structures of Ise Bay and Chikugo Estuary were drastically altered after heavy rainfall. Short-term variability thus appears an important feature in the dynamics of Japanese estuaries and coastal areas, while continental systems are rather subject to long-term changes attributable to the seasonal flood (Eyre and Twigg, 1997; Thompson, 1998; Harrison et al., 2008).

Phytoplankton abundance in the Yura Estuary was high in summer and low in winter (Figs. 2 and 3). This differs from the typical seasonal pattern consisting of phytoplankton blooms in spring and autumn. Many estuaries are characterized by minimum productivity in winter, and maximum productivity in summer rather than spring (Boynton et al., 1982). In all seasons, high nutrient concentration was supplied from the upper river to the Yura Estuary (Fig. 3e), although the concentration was apparently lower than that in the highly urbanized Pearl River (Harrison et al., 2008). A possible explanation for temporal differences in productivity in these estuaries is that rather than being limited by nutrient availability, phytoplankton would be light and/or temperature limited, so that production would follow the seasonal pattern of solar radiation. Some studies also reported that the low flushing rate in summer compared with that in winter allow longer residence time for the phytoplankton, resulting in higher productivity (Mann, 2000). It has also been shown in other estuaries that the main source of nutrients comes from recycling by the benthic community, which activity peaks with high summer temperatures (Mann, 2000; Harrison et al., 2008). However, it is not likely to be the case of the Yura Estuary, as nutrient concentration was higher in the surface river water than in the bottom seawater (Fig. 6).

The subsurface chlorophyll maximum is another important characteristic of the Yura Estuary (Figs. 2, 5 and 6). The saltwater intrusion and subsequent stratification were essential for phytoplankton production. In the upper layer, where salinity was low, the freshwater chlorophytes were predominant (Kasai, unpublished data). The freshwater phytoplankton demands more abundant nutrients than marine phytoplankton to grow, and its production is usually low in Japanese rivers because of the short residence time (Murakami, 1996). Therefore, chlorophyll concentration remained low in 
the upper freshwater layer even in summer (Figs. 3, 5 and 6). On the contrary, phytoplankton was abundant just below the halocline in the river and at the river mouth, where salinity was high (Fig. 5). The surface nutrient and chlorophyll concentrations (Fig. 7) indicated that nutrients from the upper river were transported until the river mouth and transformed into phytoplankton production there. In the Swan River, phytoplankton blooms where freshwater meets saline water, consistent with our results (Thompson et al., 1998). From the difference between the observed nitrate + nitrite concentration at the river mouth $(10 \mu \mathrm{M}$ in August and $17 \mu \mathrm{M}$ in September $)$ and the predicted value of $25 \mu \mathrm{M}$ (August) and $28 \mu \mathrm{M}$ (September) from the mixing lines (Fig. 7a), about $15 \mu \mathrm{M}$ (August) and $11 \mu \mathrm{M}$ (September) of nitrate + nitrite were used for primary production at the river mouth. Using the Redfield ratio $(\mathrm{C} / \mathrm{N}=6.6)$ and assuming $\mathrm{C} / \mathrm{Chl}$ ratio for fresh phytoplankton as 80 (Parsons et al., 1984), the concentration of chlorophyll of newly produced phytoplankton was estimated to be 15 $\mu \mathrm{gL}^{-1}$ (August) and $11 \mu \mathrm{gL}^{-1}$ (September). These concentrations correspond to the observed increases in chlorophyll concentration in the middle layer of the river and at the river mouth (Figs. 6 and 7), and suggest that the phytoplankton produced at the river mouth was transported upstream through the middle layer by the estuarine circulation.

It has been hypothesized that physical processes and biological-physical interactions play critical roles in the formation of subsurface chlorophyll maxima (e.g. Dekshenieks et al., 2001). Our results suggest that the river provides the main source of new nutrients fueling phytoplankton blooms at the mouth. Phytoplankton would then be transported upstream through the middle layer by the estuarine circulation. Another plausible mechanism is the vertical mixing of riverine nutrients and marine phytoplankton at the interface of the upper and lower layers (Harrison et al., 2008). In our observations, middle layer chlorophyll concentration was sometimes larger than that at the river mouth (Fig. 2), suggesting additional production along the interface. Future studies should assess whether the production at the river mouth or at the interface inside the river is the major contributor for the production of the middle layer chlorophyll maximum.

It is important to elucidate the mechanism of secondary and/or tertiary production, as the rich production of coastal ecosystems is mainly supported by the nutrient input from rivers. For example, in the Gulf of St. Lawrence, interannual variability in lobster landings between 1950 and 1985 was positively correlated to the variability in the St. Lawrence River runoff (Drinkwater et al., 1991). However, there are also cases in which secondary (or higher) production is negatively related to freshwater input. This is the case in the mouth of the Fraser River where salmon and 
herring production is lower during wet summers (Beamish et al., 1994). Mechanisms driving spatial and temporal variability in secondary production thus need more investigation for a better understanding of coastal ecosystems.

\section{Acknowledgments}

The authors are grateful to the captain of R/V Ryokuyo-Maru of Maizuru Fisheries Research Station, Kyoto University, for his helpful assistance in the field surveys. This research was partly supported by a Grant in Aid for Scientific Research from the Ministry of Education, Science, Sports and Culture of Japan. DR benefited from a postdoctoral fellowship of the Japan Society for the Promotion of Science.

\section{References}

Beamish, R.J., Neville, C.M., Thomson, B.L., Harrison, P.J. and St. John M., 1994. The effect of the Fraser River discharge on interannual production of Pacific salmon and herring in the Strait of Georgia. Can. J. Fish. Aquat. Sci. 51, 2843-2855.

Boynton W.R., Kemp, W.M. and Keefe, C.W., 1982. A comparative analysis of nutrients and other factors influencing estuarine phytoplankton production. In: V.S. Kennedy (Editor), Estuarine Comparisons. Chapman and Hall, New York, pp. 69-90.

Dekshenieks, M.M., Donaghay, P.L., Sullivan, J.M., Rines, J.E.B., Osborn T.R. and Twardowski, M.S., 2001. Temporal and spatial occurrence of thin phytoplankton layers in relation to physical processes. Mar. Ecol. Prog. Ser. 223, 61-71.

Drinkwater, K.F. and Frank, K.T., 1994. Effects of river regulation and diversion on marine fish and invertebrates. Aquatic Conservation 4, 135-151.

Drinkwater, K.F., Harding, G.C., Vass, W.P. and Gauthier, D., 1991. The relationship of Quebec lobster landings to freshwater runoff and wind storms. In: J.C. Therriault (Editor), The Gulf of St Lawrence: Small Ocean or Large Estuary? pp. 179-187. Ottawa: National Research Council of Canada. Canadian Special Publication of Fisheries and Aquatic Sciences No. 113.

Dyer, K.R., 1996. Estuaries -A physical introduction-. John Wiley \& Sons, Chichester, 195pp.

Eyre, B. and Twigg, C., 1997. Nutrient behaviour during post-flood recovery of the Richmond River Estuary northern NSW, Australia. Est. Coast. Shelf Sci. 44, 311-326.

Harrison, P.J., Yin, K., Lee, J.H.W., Gan, J. and Liu, H. Physical-biological coupling in the Pearl River Estuary. Cont. Shelf Res. 28, 1405-1415. 
Ibanez, C., Pont, D. and Prat, N., 1997. Characterization of the Ebre and Rhone estuaries: A basis for defining and classifying salt-wedge estuaries. Limnol. Oceanogr. 42, 89-101.

Kasai, A., Hill, A.E., Fujiwara, T. and Simpson, J.H., 2000. Effect of the Earth's rotation on the circulation in regions of freshwater influence. J. Geophys. Res. 105, 16961-16969.

Mann, K.H., 2000. Ecology of coastal waters. Blackwell Science, Massachusetts, 406.

Murakami, T., 1996. Potamoplanktonic algae. In: Y. Saijo, S. Okuda (Editors), Tidal Rivers -Their natural state and human-induced changes-. Nagoya Univ. Press, Nagoya, pp. 123-150.

Nishida, H., 1980. Improved tidal charts for the western part of the North Pacific Ocean. Rep. Hydrogr. Res. 15, 55-70.

Parsons, T.R., Takahashi, M. and Hargrave, B., 1984. Biological Oceanographic Processes $3^{\text {rd }}$ edition. Pergamon Press, Oxford, 344pp.

Sugimoto, R., Kasai, A., Yamao, S., Fujiwara, T. and Kimura, T., 2004. Variation in particulate organic matter accompanying changes of river discharge in Ise Bay. Bull. Jpn. Soc. Fish. Oceanogr. 68, 142-150.

Sugimoto, R., Kasai, A., Yamao, S., Fujiwara, T. and Kimura, T., 2006. Short-term variation in behavior of allochthonous particulate organic matter accompanying changes of river discharge in Ise Bay, Japan. Est. Coast. Shelf Sci. 66, 267-279.

Suzuki, K., Sugimoto, R., Kasai, A., Shoji, J., Nakayama, K. and Tanaka, M., 2009. Dynamics of particulate organic matter in the estuarine turbidity maximum of the Chikugo River, Ariake Sea, in summer. Bull. Jpn. Soc. Fish. Oceanogr., in press. (in Japanese, with English Abstr.)

Thompson, P.A., 1998. Spatial and temporal patterns of factors influencing phytoplankton in a salt wedge estuary, the Swan River, western Australia. Estuaries. 21, 801-817.

Unoki, S., 1993. Physical oceanography in coastal areas. Tokai University Press, Tokyo, 672pp. (in Japanese)

Wolsnski, E., 2007. Estuarine ecohydrology. Elsevier, Amsterdam, 157pp. 


\section{Figure captions}

Figure 1 Location and bathymetry of the Yura Estuary with standard hydrographic stations $(\bullet)$ and hydrographic stations where nutrient and chlorophyll concentrations were also assessed (o). TS stands for the Tsushima Strait.

Figure 2 Longitudinal distributions of temperature, salinity and chlorophyll + pheophytin concentration measured on 25-26 February 2008 and 22-23 May 2007. Distance from the river mouth is represented as positive if downstream-ward or negative if upstream-ward.

Figure 3 Time series (April 2006 to March 2008) of (a) the salt wedge distance, (b) river discharge in Fukuchiyama, (c) sea level in Maizuru, (d) chlorophyll + pheophytin maximum concentrations at $6 \mathrm{~km}$ upstream-side (solid circles) and $3 \mathrm{~km}$ offshore from the river mouth (open squares), and (e) nitrate + nitrite concentrations at $6 \mathrm{~km}$ upstream-side (solid circles) and $3 \mathrm{~km}$ offshore from the river mouth (open squares).

Figure 4 Multiple regression analysis of observed salt wedge distance as a function of river discharge and sea level. The regression equation is $y=-0.16 x_{1}+$ $0.09 x_{2}+6.5$, where $y$ is the salt wedge distance, $x_{1}$ the river discharge and $x_{2}$ the averaged daily mean sea level on the sampling day and the previous day.

Figure 5 Vertical profiles of salinity and chlorophyll + pheophytin concentration in the river (6 km upstream from the river mouth) on 22 September 2006.

Figure 6 Longitudinal distributions of nitrate + nitrite, chlorophyll + pheophytin concentrations and salinity on 22-23 August 2007.

Figure 7 (a) Surface nitrate + nitrite and (b) Chlorophyll + pheophytin concentrations observed on 22-23 August (circles) and 18-19 September (triangles) 2007, as a function of salinity. Filled, gray and open symbols represent concentrations observed in the river, at the river mouth and in the sea area, respectively. 

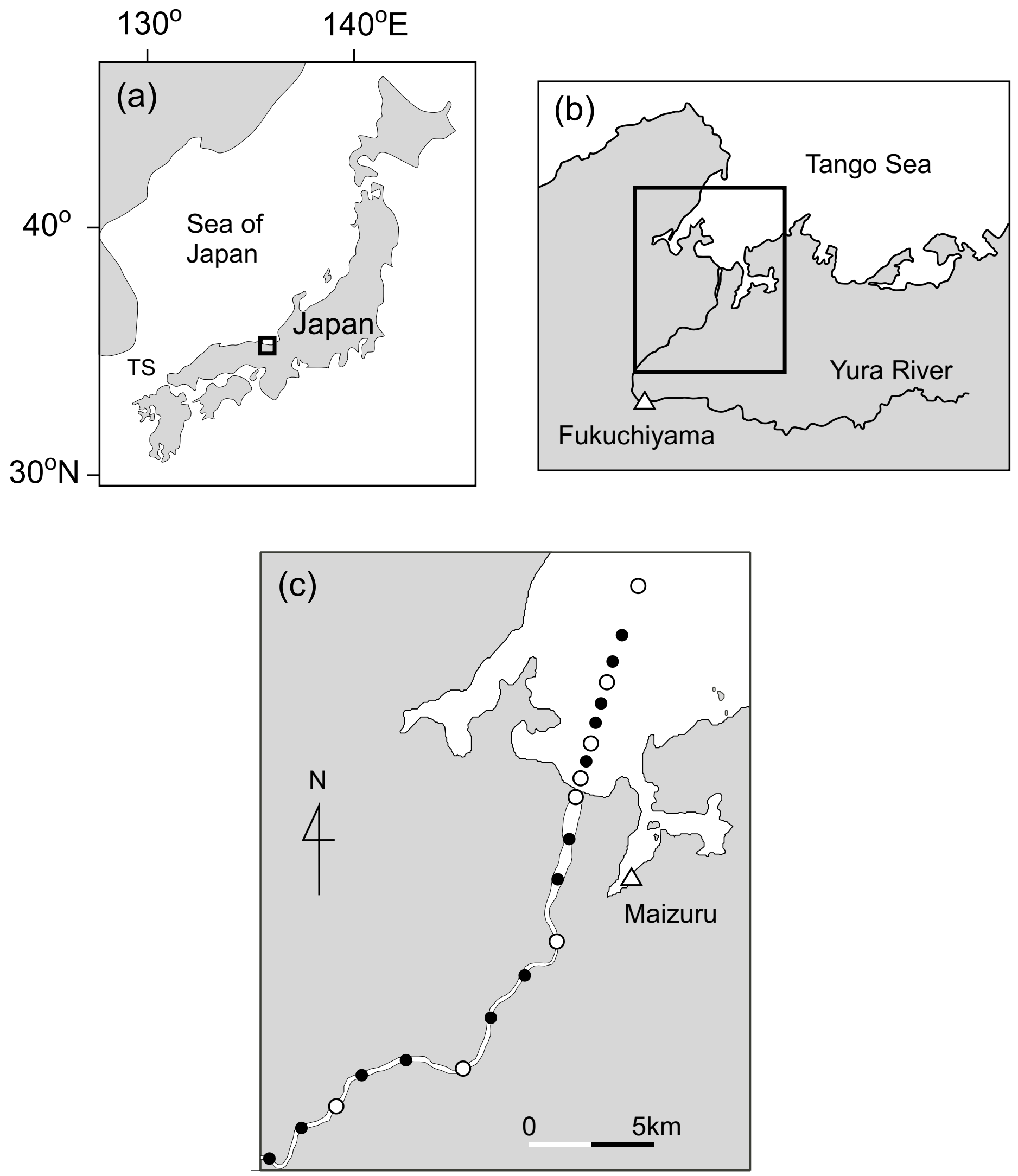

Fig.1 Kasai et al. 

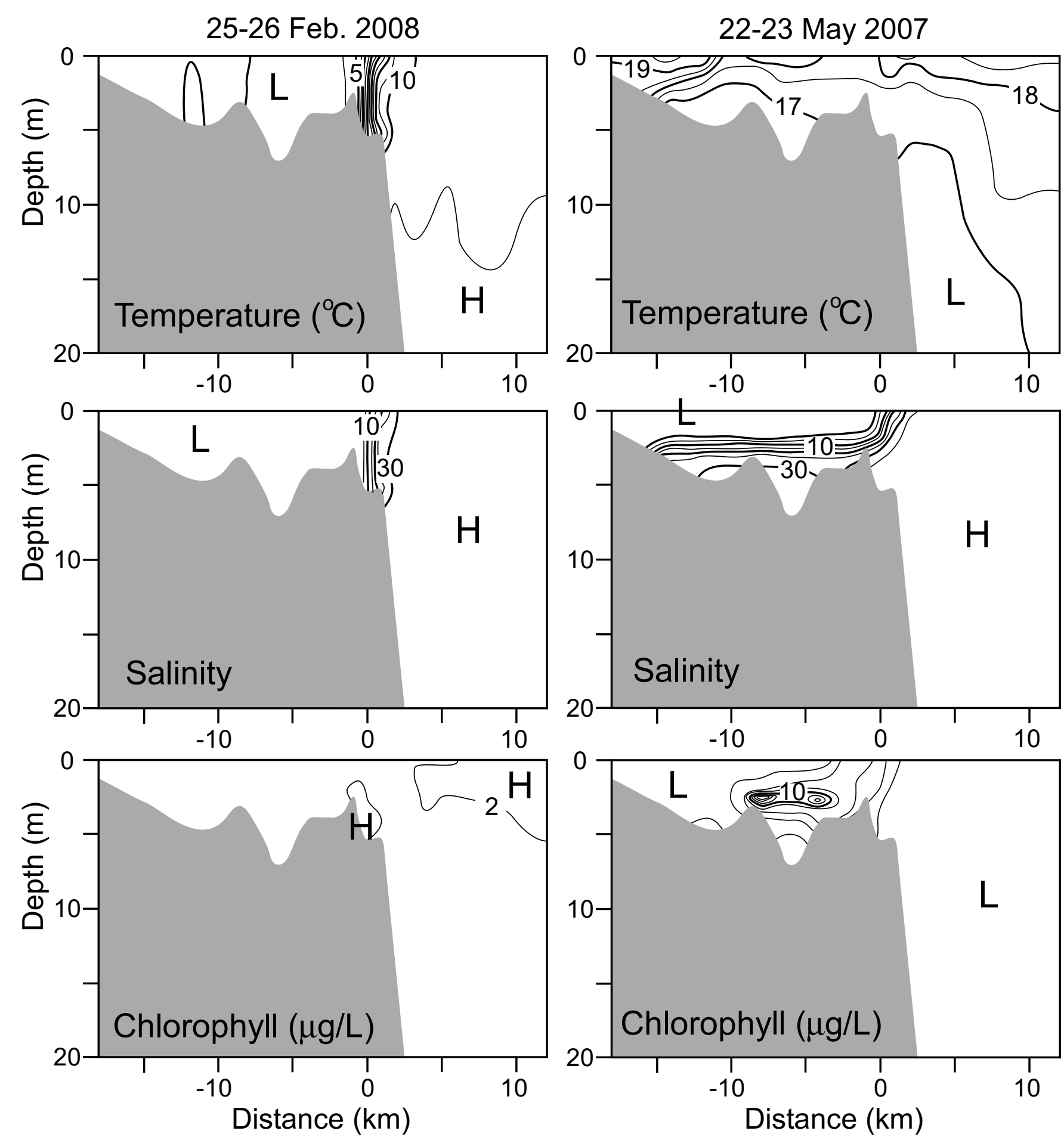

Fig. 2 Kasai et al. 

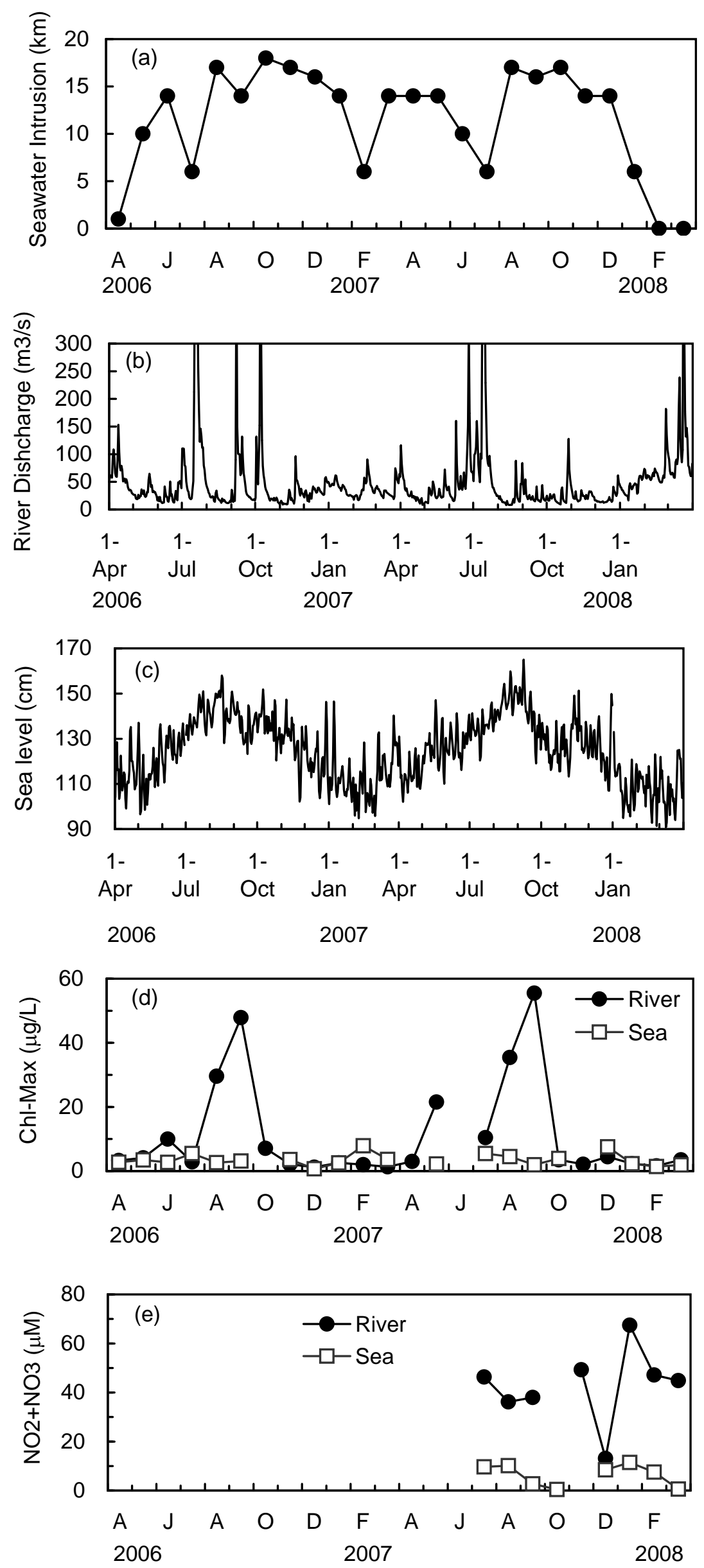

Fig. 3 Kasai et al. 


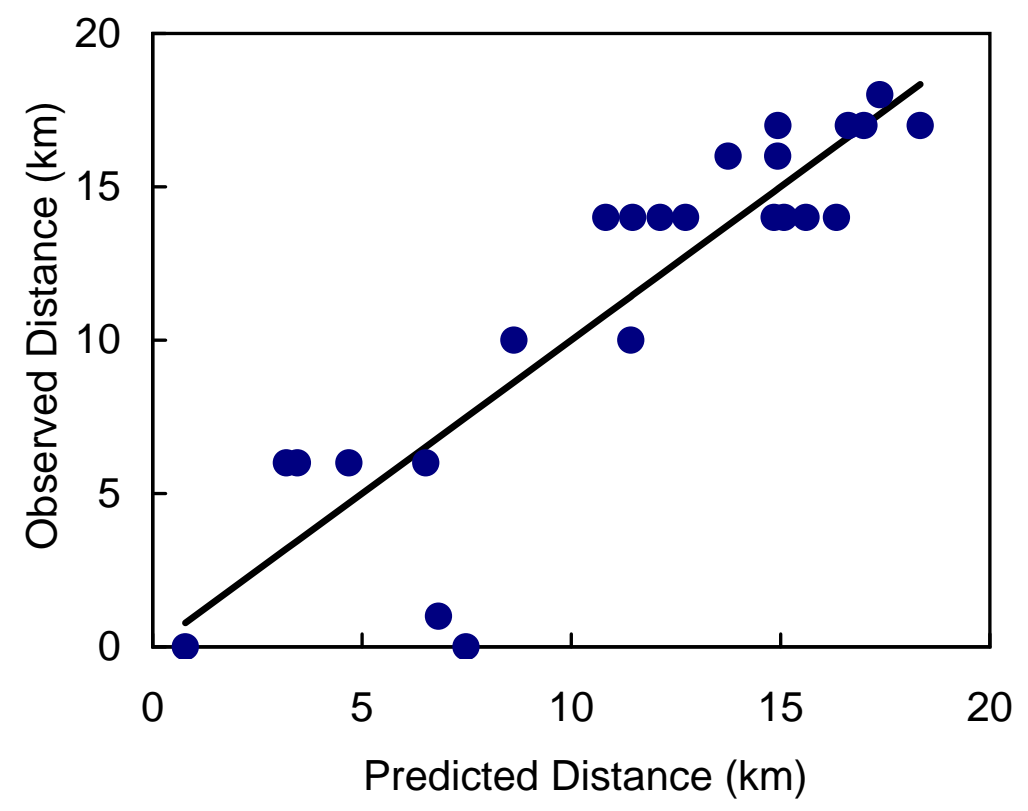

Fig. 4 Kasai et al 
Chl. $(\mu \mathrm{g} / \mathrm{L})$

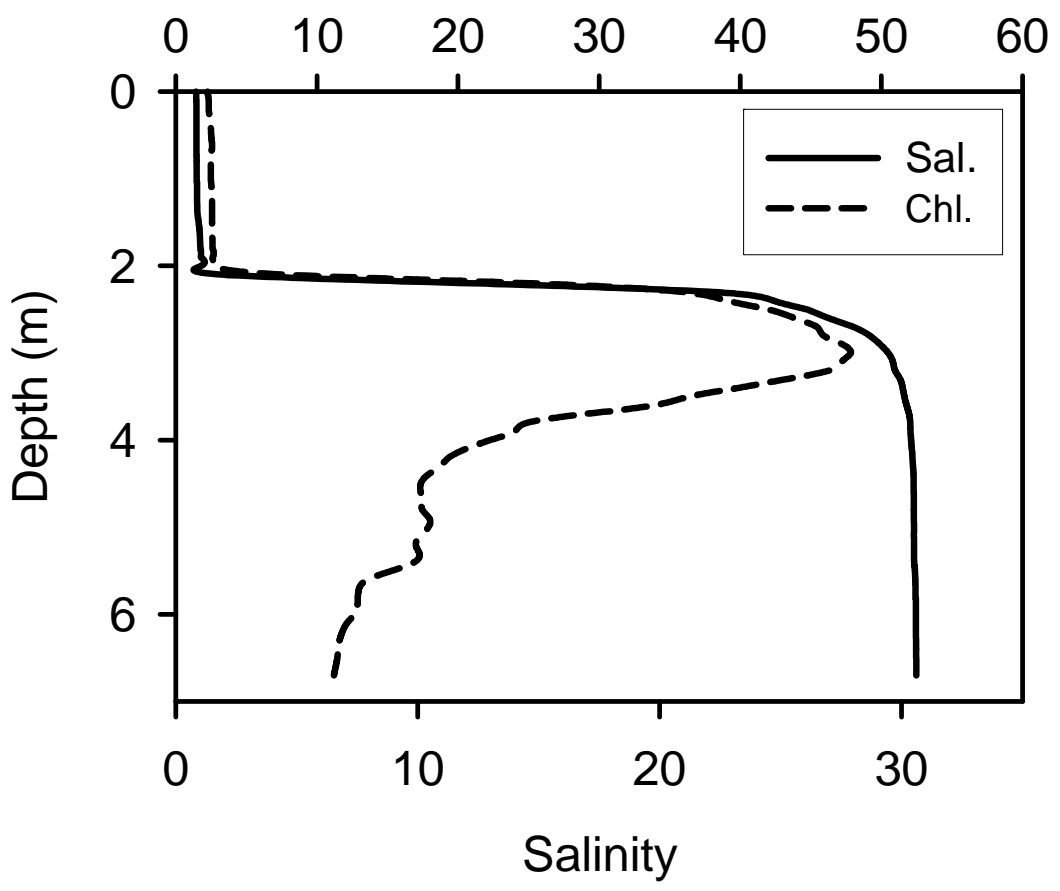

Fig. 5 Kasai et al. 

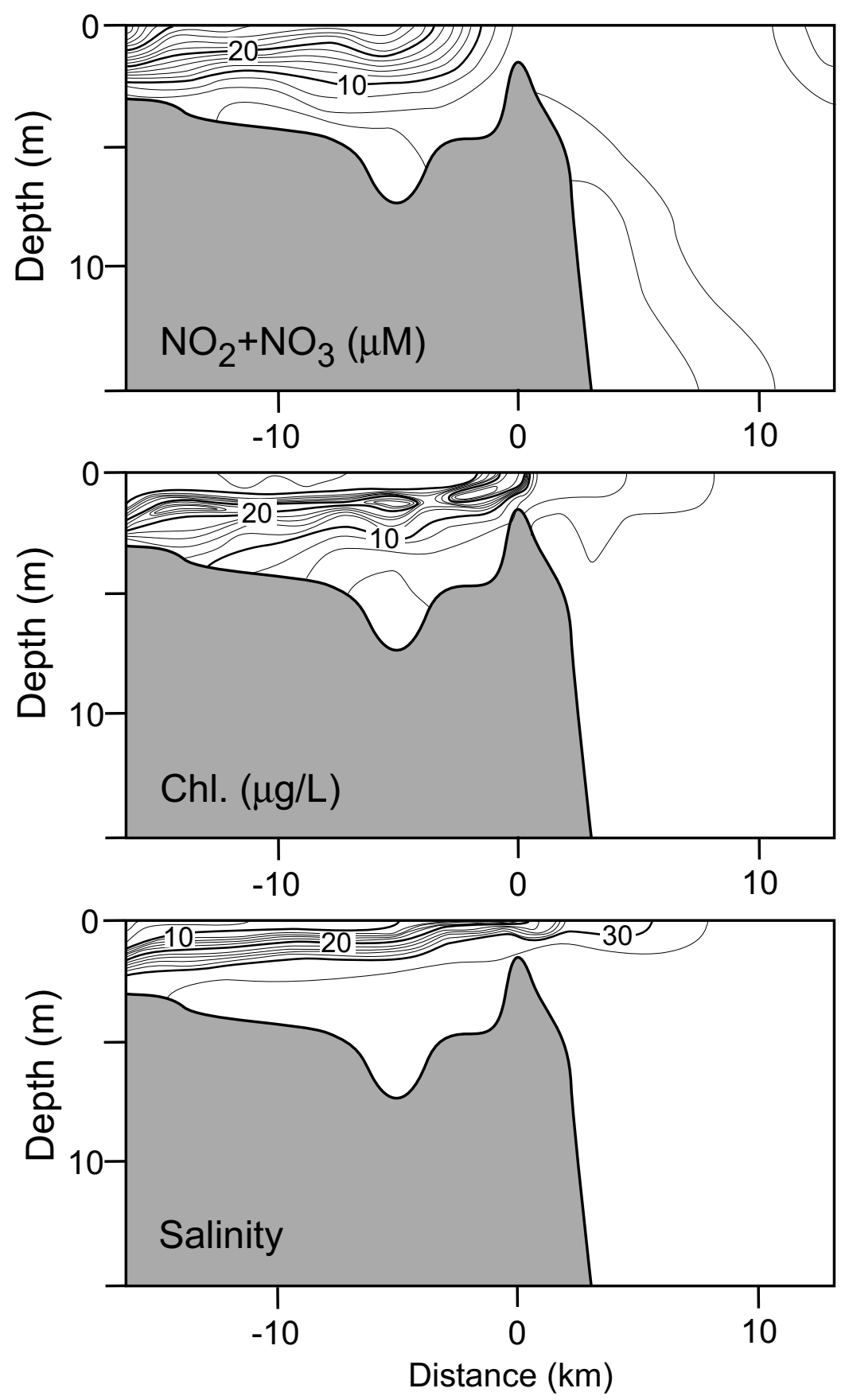

Fig. 6 Kasai et al. 

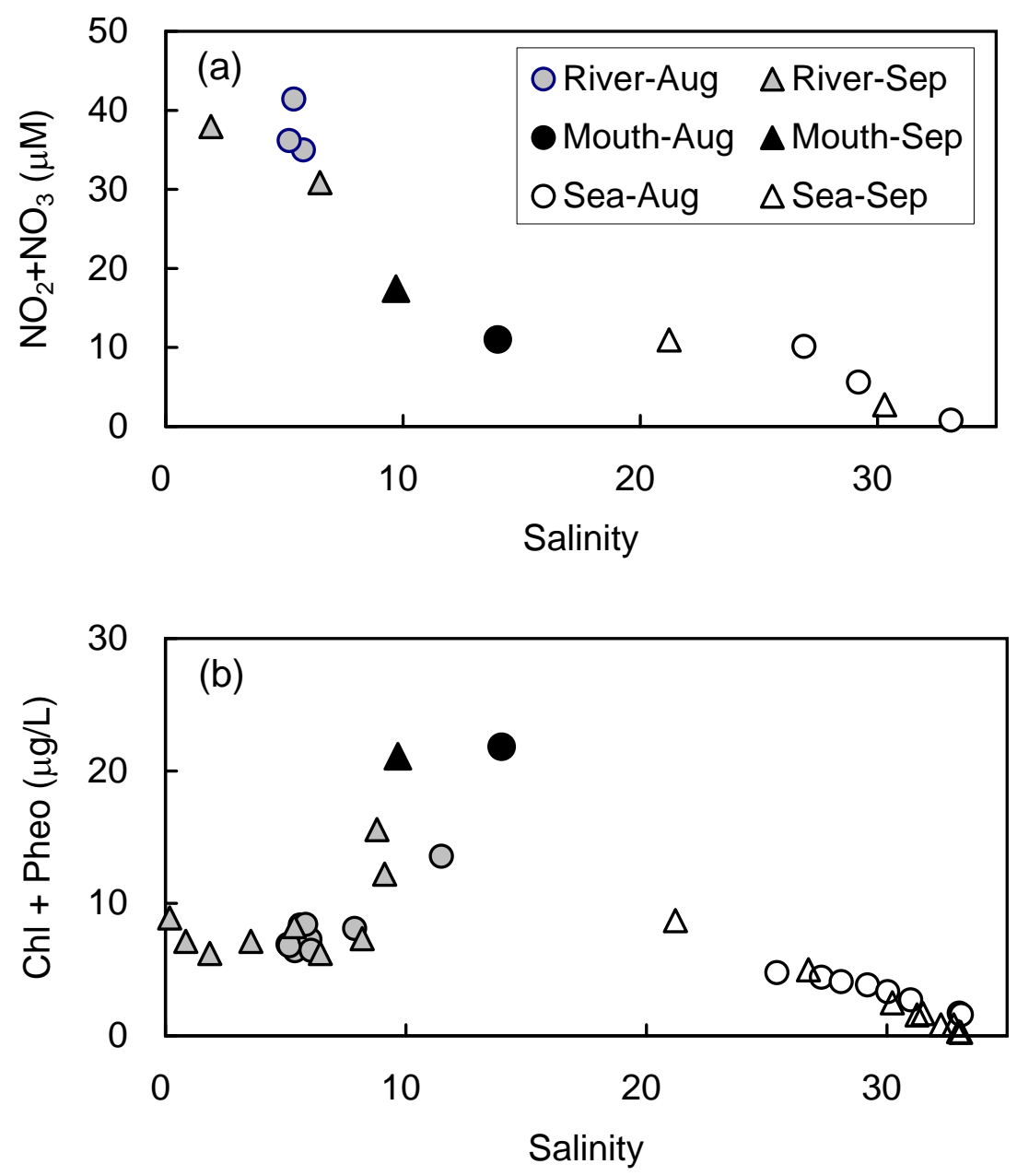

Fig. 7 Kasai et al. 